\title{
Restoring a Fractured Central Incisor: A Challenge to Overcome
}

\author{
Hadyaoui Dalenda*, Azouzi Ines, Kalghoum Imen, Belhssan Harzallah and Cherif Mounir \\ Department of Fixed Prosthodontics, University of Monastir, Tunisia
}

Received: September 01, 2017; Published: September 13, 2017

*Corresponding author: Hadyaoui Dalenda, Associate professor, Department of Fixed Prosthodontics, Faculty of Dental Medicine, University of Monastir, Tunisia

\begin{abstract}
Restoring a single central incisor should aim at preserving the affected tooth as well as re-establishing function and esthetic. This clinical report describes a patient with compromised smile due to the fracture of the tooth number 11 which was immediately restored by resin waiting for the healing process after the trauma. A zirconia based ceramic restoration was performed. Basic guidelines were followed to guarantee a natural mimicry of the restoration.
\end{abstract}

Keywords: Single Upper Central Incisor; Dental Trauma; Esthetics; Zirconia; Shade selection

Abbreviations: TMD: Temporo Mandibular Joint Disorders

\section{Introduction}

The maxillary central incisors have an effect on the visual aspect of a person either positively or negatively. In fact achieving a natural mimicry of the single maxillary central incisor restoration with the adjacent dentition is a real challenge. Thus an accurate match of a single incisor crown with the supporting tissues leads to a near mirror image [1]. When the central incisor is decayed or fractured, the situation is complicated as it needs a prior reconstruction. Currently, fiber posts and cores solve the problem thanks to their elastic behavior. Their modulus of elasticity is similar to that of dentin, unlike metal or ceramic posts [2,3]. The restoration will be instantly compared with the natural counterpart. Hence the slightest differences of shape and color will be immediately perceived. Knowing that the patient's expectations in this case are normally very high, this integration of the restored central tooth is more challenging for both the clinician and the ceramist.

This may be one of the most critical procedures in esthetic restorative dentistry [1]. To match natural adjacent teeth, all ceramic crowns offer better potential than metal-ceramic ones [4]. Ceramic materials are promising allowing natural mimicry thanks to their optical properties. There is a wide range of available. The correct one must be chosen. Zirconia based crowns are more and more selected as they ally improved mechanical properties, enhanced soft tissue biocompatibility promising longevity and esthetics [5-8]. Nevertheless, the laboratory technician should give due care to the appropriate thickness of ceramic $[9,10]$ as well as to the shade selection. Numerous guides have been developed through the years in order to enhance shade selection and facilitate the communication with the ceramist. The VITA 3D master shade guide is recommended: it is the only one which allows the assessment of the luminosity being the most important component. Special shade tabs are also required for the opalescence, fluorescence and translucency of natural teeth $[11,12]$.

Nowadays computerized shade selection are of great value to reduce the subjective component of the procedure as they enhance the objective assessment of tooth shade $[1,13]$. Matching the surface texture is as paramount as matching the shade since it can affect brightness, color saturation and luster. Mirror image between central incisors is expected [14]. However, minor deviations make the smile more dynamic and offer natural effect. Researchers proved that in only $14 \%$ of cases, a perfect symmetry is observed contrary to a slight asymmetry which is often found both in length and width. This should not exceed $0.3 \mathrm{~mm}$ in width and 0.4 in length otherwise; it can be easily perceived [15].

Faced with a compromised central incisor, many solutions are available and the practitioner has to choose the appropriate one. Rehabilitation of the fractured tooth number 11 was performed with a fiber post and core supported prosthetic restoration. The purpose of this study case is to outline the treatment approach and to highlight the different guidelines to follow in order to obtain a successful all ceramic single crowns on the maxillary central incisor in order to overcome this challenge. 


\section{Case Presentation}

A 25-year-old woman was referred by the treating endodontic for restoration of a fractured central incisor. The tooth received a traumatic blow. To guarantee successful endodontic outcomes, adequate root canal system treatment was performed. In addition, a provisional composite was realized, providing immediate esthetic satisfaction. This was reliable short-term restoration of the crownroot fractured tooth during healing period and recovery of the periodontium (Figures 1 \& 2) [16]. The patient's medical history was non-contributory. We required interacting with the patient to set expectations. First, the patient was recommended to take up initial periodontal preparation and to intensify oral hygiene before starting the rehabilitation process [17]. We proceeded by taking natural and full smile photographs with and without shade tabs (VITA 3D Master shade guide), Black and white digital images were used to select the correct value [17].

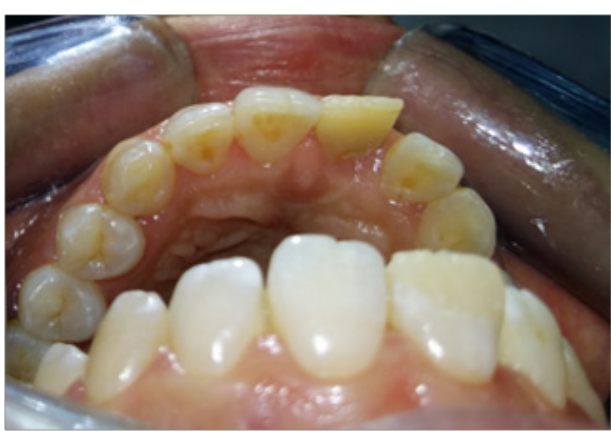

Figure 1: Initial case: the right central incisor was fractured at a lingual-distal angle just apical to the cement-enamel junction palatal view of a large defective composite restoration in tooth 11

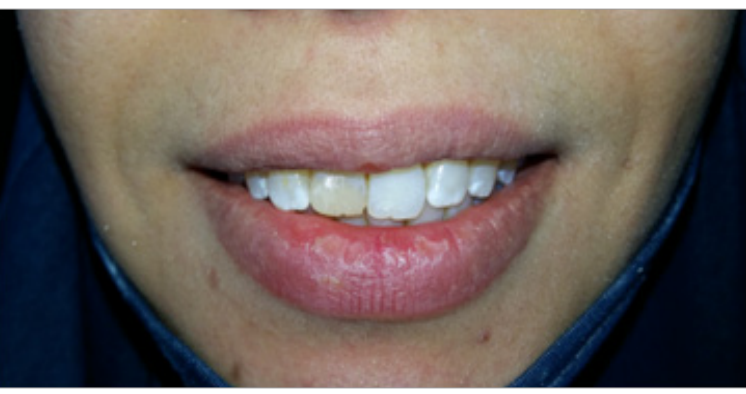

Figure 2: The fractured central incisor restored with resin.

The existing composite restoration was removed. The amount of the remaining tooth structure was evaluated as well as the level of the fracture line. Approximately $90 \%$ of the clinical crown of tooth number 11 was fractured. $1 \mathrm{~mm}$ of tooth structure just coronal to the cement-enamel junction was revealed. Gingivectomy using a new diamond-tipped bur was done to convert the sub gingival fracture to a supragingival one (Figure 3) [18] 2 to $3 \mathrm{~mm}$ probing depths. Radiographic assessment revealed that the crown-to-root ratio greater than $1(\mathrm{RC} / \mathrm{RR}>1)$. There was associated root fracture, periapical radiolucency nor resorption. The patient was deemed to have acceptable occlusal function: either evidence of attrition on the posterior or anterior teeth nor mobility due to functional forces.
No symptoms of Temporo mandibular joint disorders (TMD) were disclosed [17]. Zirconia is probably, the best used in such a clinical scenario without compromising the value of the definitive result, thanks to its semi-opaque aspect which mimics the neighboring opaque, high value teeth [19]. In addition, the intra-sulcular palatal margins contraindicates the bonding procedure [1].

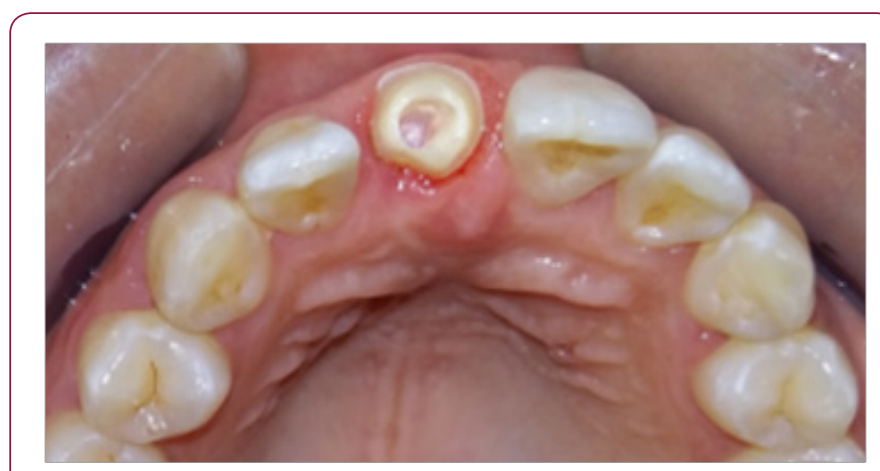

Figure 3: Preparation of abutment: occlusal view.

\section{Preparation Design}

\section{Metal-free restorations require strict preparation techniques}

Proximal walls are ideally tapered between 6 and $10^{\circ}$, they should be rounded with no sharp angles so as to avoid any internal stress in the crown. Moreover, margins should be extremely smooth and uniform to guarantee precise, well-fitting and strong ceramic ones. These principles of tooth preparation are meant to ensure good mechanical behavior of the ceramic material thus preventing fracture and cracking [11]. Once the preparations undertaken, temporary crown, with precisely fitting and highly polished margins, was fabricatedutilizing the silicone matrix formed on the modified study model. It's a key to success in such cases [9]. A well made temporary crown will immediately satisfy the esthetic, functional and biologic requirements (Figure 4). Thus, time constraints may be removed. A retraction was made to allow the impression of additional tooth structure beyond the margins, so that we can help the technician create the correct emergence profile [4].

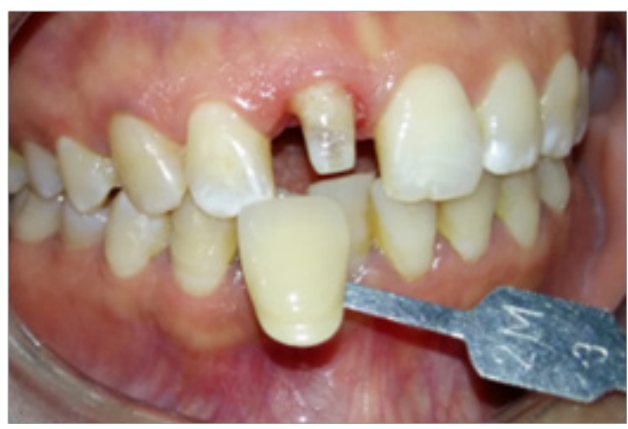

Figure 4: Base shade selection under controlled lightning.

\section{Shade Selection}

Accurate shade selection and shade matching are a paramount step for achieving natural mimicry of the central incisor (Figure 5). From an esthetic perspective, it may be the most difficult tooth to fabricate due to the association of many variables such as 
mesmerism, individual characterizations and variations in lighting and illumination type $[11,13]$. If not regarded, they all contribute to reducing predictability of providing the desired shade $[1,20,16]$. This primordial step should be taken at the beginning of the impression appointment before teeth dehydrate and its color changes (become brighter). The reproduction of the shape is a similarly important parameter to achieve the perfect restoration. A shade map was drawn with all internal and external characterizations, variations in chroma and translucency, as well asirregularities of the incisal edge, Crack lines and incisal halo. They all were identified, recorded and communicated to the dental ceramist. The level of reproduction of such features depends on the patient acceptance to guarantee the success (Figure 6) [1].

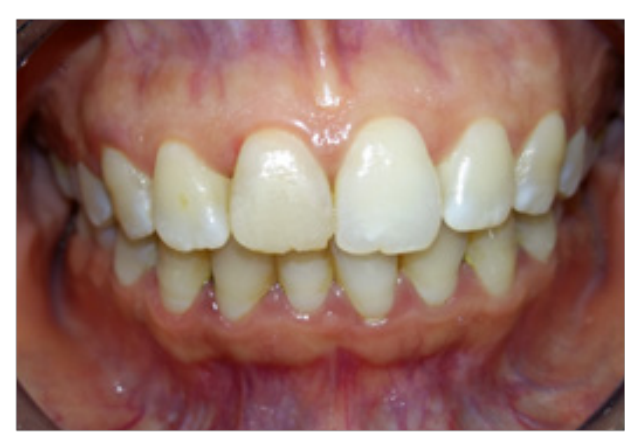

Figure 5: Provisional Restoration: Guide of the final restoration.

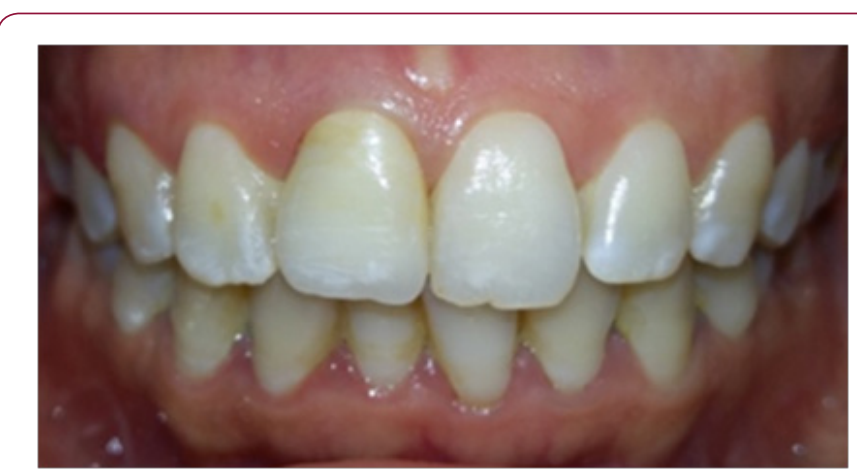

Figure 6: Satisfying esthetic outcome: characterizations reproduction, periodontal integration and function.

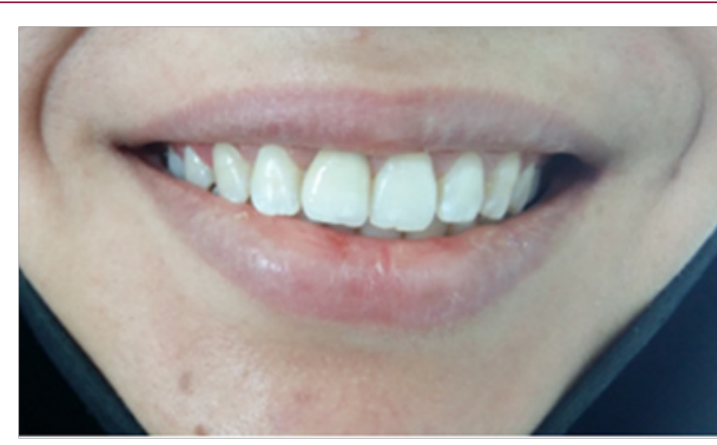

Figure 7: Natural aspect of the restoration through dynamic lip view.

Besides the material used for the understructure, the layering porcelain was carefully selected. Occlusion was carefully checked and adjusted [18]. An esthetic try-in, before final staining and glazing, was carried out to verify the crown morphology and the color [17]. As the patient expectations were very high, this require care, skills and talent of the restorative team [11]. Multiple tryINS is often required. We can even be forced to remake the crown until achieving a satisfactory result [4]. The ceramic crown was cemented using glass ionomer reinforced by resin which provides good seating besides sufficient working time, good fluidity and easy trimming [21]. At the end of the treatment, the patient was pleased with the results and no longer hides her smile (Figure 7).

\section{Discussion}

Despite being discussed several times in the literature, the process of matching a central maxillary incisor crown, to a near mirror image of the controlateral tooth in all esthetic, functional, biological and material dimensions, is still a supreme challenge to all members of the restorative team [1,22]. Undoubtedly, understanding the technical difficulties helps the clinician set and communicate expectations appropriately with the patient [20]. What makes matching this tooth difficult mostly are that it is the anterior one. It is centrally located in the esthetic zone. Therefore, the slightest variations are generally immediately perceived.

In addition, when restoring one tooth, the degree of modifications, that can be imposed, will be limited as the tooth (to be matched to) dictates precisely the parameters of the entire restoration. A well-fitting and esthetic temporary crown must not be ignored. It will immediately satisfy the esthetic, functional and biological requirements of the dentist and the patient and allow them to carry on with treatment until achieving success [4]. Regardless of how esthetic a restoration looks, the efforts of the dentist and the technician are not worth it if it lacks durability. That's why the material must be carefully selected [11]. Thanks to technological innovations along with talented dental technician, close simulation of the natural dentition is possible [22].

However, the degree of difficulty rises considerably, even for highly experienced ceramists using the most advanced technologies, because each case is essentially a unique artistic endeavor [22]. Because of the complexity of the tooth to be matched, as shown in this case, and because the result is dependent on the dental technician, the best possible solution is to have the ceramist see the patient to actively participate in the restoration matching process [1].

\section{Conclusion}

In order to achieve and maintain efficient treatment outcomes, the case of a traumatically fractured single central incisor is very challenging for the practitioner. Esthetic and functional results must be considered when determining the proper treatment method [16]. Communication, patience, skills, artistic talent and pursuit of excellence is the key to achieve success [17]. Artistically, refining the central incisor so that it matches a controlateral tooth, obviously requires a serious team work regarding essential parameter of success such as material selection, shade matching and laboratory procedure [22]. 


\section{References}

1. Raigrodski A (2008) Managing the Challenge of Crowning the Single Central Maxillary Incisor. Journal of Esthetic and Restorative Dentistry 20(5): 337-342.

2. Pallav Mahesh Patni, Pradeep Jain, Mona Jain Patni (2016) A Conservative Approach to the Management of a Dental Trauma for Immediate Natural Esthetics. Arch Trauma Res 5(2): e29042.

3. V Seguela, A Soenen, O Laviole, M Bartala (2011) Reconstitution corono radiculaire et systèmes tout céramique. Les cahiers de prothèses $n 155$.

4. Mizrahi B (2008) Restoration of a single central incisor with an allceramic crown: a case report. International dentistry 10(3): 1-38.

5. Probster B Reiss, K Wiedhahn, M Kern, M Helfer, M Fages, et al. (2013) La Zircone Matériau d'avenir. Stratégie Prothétique : Janvier-Février (13)1: 63-68.

6. F Spear, J Holloway (2008) Which all-ceramic system is optimal for anterior esthetics? J Am Dent Assoc 139: 19S-24S.

7. Sunit Kr Jurel, Raghu wardayal singh (2017) All ceramic crown an anhanced esthetics. Indian journal of dental sciences, India.

8. Mondelli RF, Apayco LC, Trentino AC, Wang L, Ishikiriama SK (2012) Challenges of restoring an anterior maxillary tooth: The impact of fluorescence and the mock-up approach. Quintessence International 43(10): 859-862.

9. Tirlet G (2009) Couronnes céramo-céramiques, les preparations, L'information dentaire, Germany.

10. Zuppardi M (2016) Easy steps for single central restoration Australasian Dental Practice pp. 190-198.

11. S Kahng (2006) Material selection and shade matching for a single central incisor. The Journal of Cosmetic Dentistry 22(1): 80-86.

12. Sung Bin Im, Aram Torosian, Alvaro Blasi, Jimmy Londono, Remi Elkattah, et al. (2017) The Challenge of Shade Matching How to achieve more Predictable Outcomes with All-Ceramic Restorations Journal of Cosmetic Dentistry 33(1): 64-81.

13. Mehta R, Kumar A, Goel M, Kumar V, Arora T, et al. (2014) Shade Selection: Blending of Conventional and Digital Methods - An Updated Review. Journal of Oral Health review article Community Dentistry 8(2): 109-112.

14. Luís Henrique Schlichting, Kyle Stanley, Michel Magne, Pascal Magne (2015) The non-vital discolored central incisor Dilemma. The International Journal Of Esthetic Dentistry 10(4): 548-562.

15. Mauro Fradeani (2007) Réhabilitation esthétique en prothèse fixée: 1 analyse esthétique, Quintescence International pp. 352.

16. Tsurumachi T, Matsumoto S, Kobayashi Y, Ohara K, Suzuki Y, et al. (2012) Esthetic and endodontic management of a deep crown-root fracture of a maxillary central incisor. Journal of oral science 54(4): 359-362.

17. Bradley J Olson (2012) Restoration of a Fractured Central Incisor. Compendium March 33(3).

18. Tsurumachi T, Matsumoto S, Kobayashi Y, Ohara K, Suzuki Y, et al. (2012) Esthetic and endodontic management of a deep crown-root fracture of a maxillary central incisor Journal of Oral Science, Vol. 54(4): 359-362.

19. Heffernan MJ, Aquilino SA, Diaz Arnold AM, Haselton DR, Stanford CM et al. (2002) Relative translucency of six all-ceramic systems. Part II: core and veneer materials. The journal of prosthetic dentistry 88(1): 10-15.

20. Daouahi N, Hadyaoui D, Saafi J (2015) Esthetic Rehabilitation with Zirconia Based Crowns. International Journal of Oral Health Dentistry 1(1): 6-10.

21. Antunes RP, Magalhäes F, Matsumoto W, Orsi IA (1998) anterior esthetic rehabilitation of all-ceramic crowns: a case report. Esthetic dentistry 29(1): 38-40.

22. Nixon R L (2003) Cosmetic Dentistry-Dentistry's Aesthetic Mt. EverestUndetectable Restoration of a Single Discolored Maxillary Central Incisor. Oral Health 93(4): 100-106.

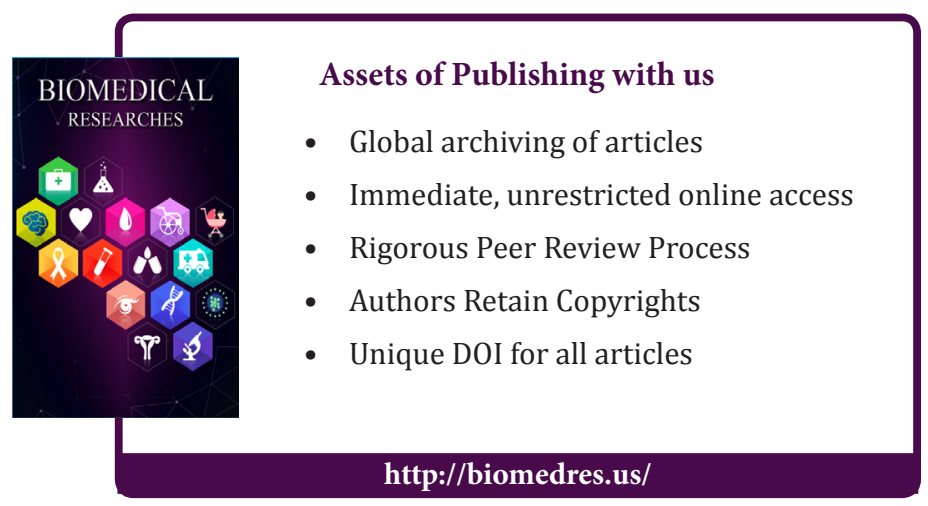

